\title{
Decrease in anti-Proteus mirabilis but not anti-Escherichia coli antibody levels in rheumatoid arthritis patients treated with fasting and a one year vegetarian diet
}

\author{
J Kjeldsen-Kragh, T Rashid, A Dybwad, M Sioud, $M$ Haugen, $\varnothing$ Førre, A Ebringer
}

\begin{abstract}
Objective-To measure Proteus mirabilis and Escherichia coli antibody levels in patients with rheumatoid arthritis (RA) during treatment by vegetarian diet.

Methods-Sera were collected from 53 RA patients who took part in a controlled clinical trial of fasting and a one year vegetarian diet. $P$ mirabilis and $E$ coli antibody levels were measured by an indirect immunofluorescence technique and an enzyme immunoassay, respectively. Results-The patients on the vegetarian diet had a significant reduction in the mean anti-proteus titres at all time points during the study, compared with baseline values (all $p<0.05$ ). No significant change in titre was observed in patients who followed an omnivorous diet. The decrease in anti-proteus titre was greater in the patients who responded well to the vegetarian diet compared with diet nonresponders and omnivores. The total IgG concentration and levels of antibody against $E$ coli, however, were almost unchanged in all patient groups during the trial. The decrease from baseline in proteus antibody levels correlated significantly $(p<0.001)$ with the decrease in a modified Stoke disease activity index.

Conclusion-The decrease in $P$ mirabilis antibody levels in the diet responders and the correlation between the decrease in proteus antibody level and decrease in disease activity supports the suggestion of an aetiopathogenetic role for $P$ mirabilis in RA.
\end{abstract}

(Ann Rheum Dis 1995; 54: 221-224)

Proteus mirabilis, a common cause of urinary tract infection, has been suggested to be of importance in RA. ${ }^{1}$ Increased proteus antibody levels have been found in patients with RA compared with healthy controls and patients with ankylosing spondylitis, sarcoidosis, and systemic lupus erythematosus, ${ }^{1-3}$ although one study found no correlation between levels of antibodies to Proteus and the Stoke disease activity index. ${ }^{4}$

In the present study we have examined the association between disease activity and proteus antibodies in RA patients during a controlled clinical trial of fasting and a one year vegetarian diet. ${ }^{5}$ We also measured IgG antibodies to Escherichia coli, and total IgG concentration, to test the species specificity of any changes in antibody titres.

\section{Patients and methods}

PATIENT POPULATION AND STUDY DESIGN Details of the RA patients who took part in this controlled clinical trial of fasting and a one year vegetarian diet have been given elsewhere. ${ }^{5}$ Briefly, 53 patients were allocated randomly to a treatment group $(n=27)$ or a control group $(n=26)$. The patients in the treatment group were sent to a health farm for a period of four weeks. During the first seven to 10 days at the health farm the patients fasted; during the subsequent 3.5 months the patients followed a gluten free vegan diet (a vegetarian diet without milk and dairy products), followed by a lactovegetarian diet during the remaining nine months of the study period. ${ }^{5}$ The patients in the control group had a four week stay at a convalescent home, and they continued to follow their normal omnivorous diet throughout the whole study period. Ten patients were withdrawn from the treatment group, and nine from the control group, during the course of the study. ${ }^{5}$

Clinical examinations were performed and blood samples collected at baseline and after one, four, seven, 10 , and 13 months. ${ }^{5}$ Serum samples were stored at $-20^{\circ} \mathrm{C}$ until required for analysis.

The patients in the vegetarian diet group were subsequently divided into diet responders and diet non-responders depending on the clinical result of the vegetarian diet, as described previously. ${ }^{6}$ Briefly, a patient was categorised as a diet responder if there had been a substantial improvement in three of six core variables (number of swollen joints, functional disability, pain score, number of tender joints, patient's global assessment and erythrocyte sedimentation rate) at all the last three clinical examinations. This distinction was made before the antibody analyses were carried out.

DISEASE ACTIVITY INDEX

To study the relationship between disease activity and the levels of antibodies against $P$ mirabilis and $E$ coli, we graded the disease activity at each clinical examination by means of a Stoke disease activity index, ${ }^{7}$ modified 
slightly by replacing the proximal interphalangeal joint synovitis score with the total number of swollen joints.

DETERMINATION OF PROTEUS ANTIBODY TITRES $P$ mirabilis (B17) was cultured as previously described. ${ }^{1}$ Multitest eight well glass slides (Flow Laboratories, Ayrshire, Scotland) were used for the fluorescence microscopy. Ten microlitres of the bacterial suspension was applied to each well after appropriate adjustment of the bacterial concentration. The slides were dried and subsequently fixed with glutaraldehyde $0.25 \%(\mathrm{v} / \mathrm{v})$ in phosphate buffered saline containing $0 \cdot 1 \%$ azide (PBS-A). The slides were then washed with PBS-A, rinsed in distilled water, dried, and finally stored at $-20^{\circ} \mathrm{C}$ until they were required for use.

For each test serum a dilution series was prepared, starting with $1 / 10$ in PBS-A and continuing with doubling dilutions. After application of $10 \mu \mathrm{l}$ of diluted serum to each well, the slides were incubated in a humid chamber at $37^{\circ} \mathrm{C}$ for 30 minutes, washed with PBS-A, rinsed with distilled water, and dried. Twenty microlitres of fluorescein conjugated anti-human IgG (Dakopatts, Copenhagen, Denmark) was then applied to each well, incubated and washed as described above. Finally, the slides were prepared for immunofluorescence, using a glycerol mounting medium. End point of the titration was taken as the last dilution showing definite fluorescence. The tester examining the sera was unaware which came from patients and which from controls. All sera were tested in duplicate and the means of the $\log _{2}$ transformed duplicates were used in the statistical analyses.

DETERMINATION OF E COLI ANTIBODY LEVELS Cell wall proteins of $E$ coli (strain $\mathrm{Hb} 101$ ) were prepared and used as coating antigen (50 ng/well) for an enzyme immunoassay. Unspecific binding was blocked with $0.5 \%$ bovine serum albumin (BSA), followed by washing three times in PBS-A with $0.1 \%$ Tween and $0 \cdot 2 \%$ BSA. Serum, diluted $1 / 25$ in the washing solution, was then added to wells coated or not coated with antigen. After washing, the plates were incubated with an alkaline phosphatase conjugated polyclonal rabbit antibody against human $\gamma$ chain, diluted $1 / 2000$ (Sigma, St Louis, MO, USA). The plates were washed three times and bound antibodies were visualised by addition of p-nitrophenyl phosphate disodium (Sigma) as substrate. The results were expressed as the difference in the optical density readings between antigen coated and uncoated wells on the same microtitre plate. All sera from one patient were tested on the same plate. Tests were carried out in triplicate and the median values were used in the statistical analyses.

STATISTICAL ANALYSES

To test for within group differences we used the Wilcoxon signed rank test. Kruskal-Wallis test was used for comparision of three groups. As a post hoc test for the latter comparison we used the Mann-Whitney $U$ test. Correlations were studied by Spearman's rank correlation analysis. For the patients who were prematurely withdrawn from the trial, values were extrapolated as previously described. ${ }^{5}$ In all tests, except for post hoc analyses, $p$ values less than 0.05 were considered as significant. As the post hoc analyses involved three comparisons, only those $\mathrm{p}$ values less than 0.0167 were regarded as significant for these tests.

\section{Results}

Patients who followed the vegetarian diet had a significant reduction in mean anti-proteus titre at all time points during the study compared with baseline values (after one, four, seven, 10 , and 13 months: $\mathrm{p}<0.005, \mathrm{p}<0.04$, $\mathrm{p}<0.005, \mathrm{p}<0.02$, and $\mathrm{p}<0.05$, respectively). No significant change in mean titre was observed in the omnivorous patients.

In the patients who eventually were categorised as diet responders, the mean antiproteus titre decreased significantly after one, four, seven, and 10 months $(p<0.04$, $\mathrm{p}<0.005, \mathrm{p}<0.005, \mathrm{p}<0.02)$ compared with baseline. We found significant differences between diet responders, diet non-responders, and omnivores with regard to the changes from baseline after four, seven, 10, and 13 months (table). At all these times the antibody titres were least for the diet responders; post hoc analyses revealed that the change from baseline was significantly greater in the diet responders compared with the omnivores (table).

Decrease from baseline with time for anti-P mirabilis titres, anti-E coli levels and total IgG concentrations

\begin{tabular}{|c|c|c|c|c|c|}
\hline & \multicolumn{5}{|c|}{ Time elapsed after baseline measurements } \\
\hline & 1 month & 4 months & 7 months & 10 months & 13 months \\
\hline $\begin{array}{l}\text { Anti- } P \text { mirabilis, } I g G\left(\log _{2} \text { dilution units }\right) \\
\text { Diet responders }(n=12) \\
\text { Diet non-responders }(n=15) \\
\text { Omnivores }(n=26)\end{array}$ & $\begin{array}{l}\text { NSt } \\
0.917(1.346) \\
0.600(1 \cdot 153) \\
0.269(0.982)\end{array}$ & $\begin{array}{l}\star \\
1 \cdot 250(1 \cdot 177) \\
0 \cdot 000(1 \cdot 086) \ddagger \\
0 \cdot 192(0 \cdot 970) \ddagger\end{array}$ & $\begin{array}{l}\star \star \\
1.417(1.395) \\
0.467(1.329) \\
-0.077(0.997) \ddagger\end{array}$ & $\begin{array}{l}\star \star \\
1 \cdot 125(1.316) \\
0 \cdot 200(1 \cdot 266) \\
-0.346(0.988) \ddagger\end{array}$ & $\begin{array}{l}\star \star \\
1 \cdot 042(1 \cdot 712) \\
0 \cdot 233(1 \cdot 100) \\
-0 \cdot 385(1 \cdot 235) \ddagger\end{array}$ \\
\hline $\begin{array}{l}\text { Anti- } E \text { coli, IgG }(O D) \\
\text { Diet responders }(n=12) \\
\text { Diet non-responders }(n=15) \\
\text { Omnivores }(n=26)\end{array}$ & $\begin{array}{l}\star \\
0.063(0.144) \\
-0.076(0.127) \ddagger \\
0.002(0.158)\end{array}$ & $\begin{array}{l}\text { NS } \\
0.058(0.093) \\
-0.024(0.082) \\
-0.004(0.114)\end{array}$ & $\begin{array}{l}\text { NS } \\
0.025(0 \cdot 149) \\
-0.035(0 \cdot 107) \\
0.004(0 \cdot 108)\end{array}$ & $\begin{array}{l}\text { NS } \\
0.052(0.162) \\
-0.073(0 \cdot 122) \\
-0.006(0 \cdot 117)\end{array}$ & $\begin{array}{l}\text { NS } \\
0 \cdot 089(0.209) \\
-0.062(0 \cdot 114) \\
-0.013(0 \cdot 144)\end{array}$ \\
\hline $\begin{array}{l}\text { Total IgG }(g / 1) \\
\text { Diet responders }(n=12) \\
\text { Diet non-responders }(n=15) \\
\text { Omnivores }(n=26)\end{array}$ & $\begin{array}{l}\text { NS } \\
0.908(1.262) \\
1.153(1.478) \\
0.054(1.699)\end{array}$ & $\begin{array}{l}\text { NS } \\
0 \cdot 158(1.948) \\
1.187(3.930) \\
0.027(2 \cdot 240)\end{array}$ & $\begin{array}{l}\text { NS } \\
0 \cdot 825(1 \cdot 713) \\
-0 \cdot 120(2 \cdot 208) \\
0.515(2 \cdot 990)\end{array}$ & $\begin{array}{l}\text { NS } \\
0 \cdot 517(2.076) \\
-0 \cdot 193(4 \cdot 031) \\
-0.027(3 \cdot 104)\end{array}$ & $\begin{array}{l}\text { NS } \\
0 \cdot 200(2 \cdot 098) \\
-0 \cdot 367(2 \cdot 869) \\
-0 \cdot 262(2 \cdot 741)\end{array}$ \\
\hline
\end{tabular}

Values are mean $(S D)$ of each group. $O D=$ Optical density; NS $=$ not significant. ${ }^{\star} p<0.05 ;{ }^{\star}{ }^{\star} p<0.01$; compared with baseline (Kruskal-Wallis test). $¥$ Significantly different from group of diet responders (post hoc analysis). 
In our control study for species specificity of response, the total IgG concentration did not change significantly in any of the groups during the trial, but after one month the change in the level of antibody to $E$ coli was significantly different in the diet non-responders compared with the diet responders and omnivores (table).

Changes from baseline of the modified Stoke disease activity index were correlated with the changes from baseline of the anti-proteus titres and of the $E$ coli antibody levels. Disease improvement correlated significantly with the decrease in the anti-proteus titres $\left(r_{\mathrm{s}}=0.31\right.$, $\mathrm{p}<0.001$ ) (figure) but not with the changes in the $E$ coli antibody levels $\left(r_{\mathrm{s}}=-0.012\right.$, not significant).

All statistical analyses were also performed on the original data that had not been extrapolated to account for withdrawn patients. These analyses gave almost the same results as for analyses of the extrapolated data (data not shown).

\section{Discussion}

The present study is the most comprehensive published longitudinal study of proteus antibodies in RA patients following treatment. We found a significant decline in the anti-proteus titre in the diet responders compared with diet non-responders and omnivores. Similar changes were not observed for the $E$ coli antibodies or total IgG.

The decrease in the proteus antibody titre in the diet responders further substantiates the suggestion that these antibodies are of central importance in the aetiopathogenesis of RA. $P$ mirabilis is a normal commensal component of human bowel flora. Fasting and vegetarian diet give rise to significant changes in the gastrointestinal bacterial flora. ${ }^{8} 9$ Peltonen et $a l^{10}$ have recently analysed the faecal flora collected from the patients who participated in the controlled clinical trial of fasting and one year vegetarian diet. Significant differences in the

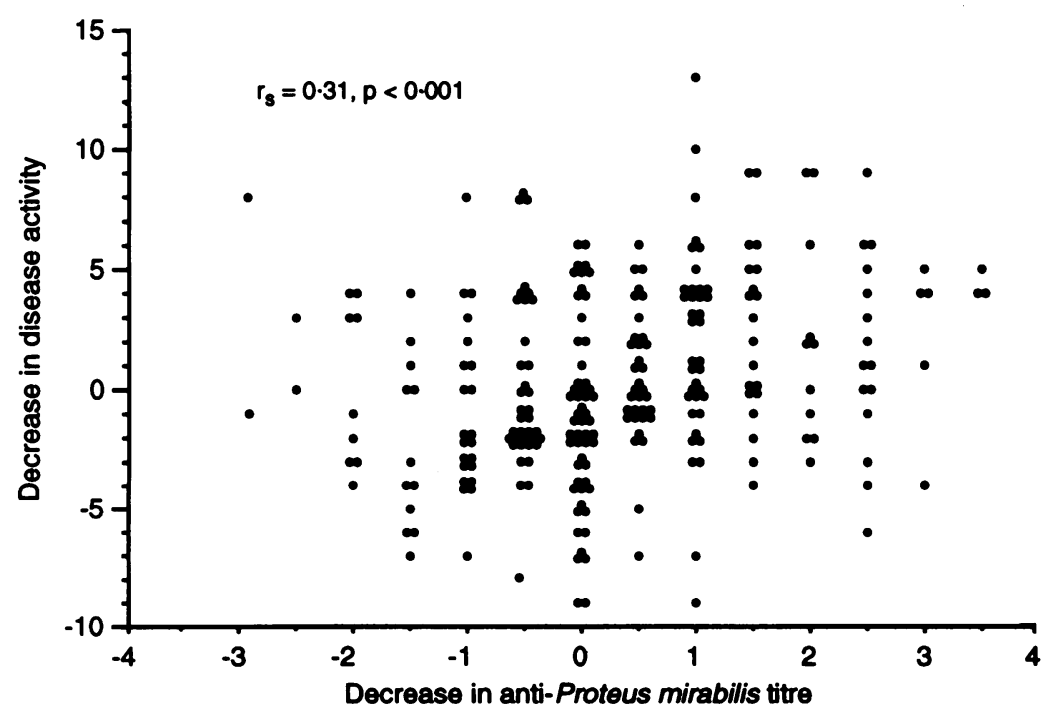

Scattergram of the decrease from baseline in anti-proteus titres in the RA patients versus the decrease from baseline in the modified Stoke disease activity index. $p$ value by Spearman rank correlation $\left(r_{s}=\right.$ correlation coefficient $)$ faecal flora were observed between samples obtained at times which coincided with pronounced clinical improvement compared with baseline, versus samples obtained at times of low or no improvement. ${ }^{10}$ However, it remains to be demonstrated if these differences were the result of a decrease in the amount of $P$ mirabilis in the faeces, which in turn might reduce the absorption of proteus antigens from the gut.

Another possible source of $P$ mirabilis is the urinary tract. In two studies Proteus bacteria were isolated significantly more frequently from midstream urine specimens obtained from patients with RA than from non-RA patients or from healthy adults. ${ }^{11}{ }^{12}$ In a recent paper McDonagh et $a l^{4}$ failed to confirm these results, but this discrepancy might be due to differences in the methods used. A shift from an omnivorous to a vegetarian diet has a profound influence on the composition of the urine ${ }^{13}$-for example, vegetarians have a greater urinary excretion of lignans and phytooestrogen metabolites than omnivores ${ }^{13}$-and some of these substances are known to possess antibacterial activity in vitro. ${ }^{14}$

A positive correlation between the concentration of $C$ reactive protein and the antiproteus titre has been reported. ${ }^{13}{ }^{15}$ In the present study we found a significant correlation between the change in anti-proteus titre and the change in a disease activity index composed of five different variables. One may argue that the reduction in anti-proteus titre in the diet responders is an epiphenomenon secondary to decreased disease activity. It is, however, difficult to conceive how decreased disease activity may influence the levels of antibody against $P$ mirabilis but not of those against E coli.

In conclusion, the present data support the suggestion of a central role for $P$ mirabilis in $\mathrm{RA}$, and this may open up new therapeutic strategies for RA. One obvious approach would be to use antibiotics to eradicate the bacteria from the urinary tract or the gut. However, to evaluate the exact aetiopathogenetic role of $P$ mirabilis, clinical trials are needed, particularly in newly diagnosed patients.

The authors gratefully acknowledge The Norwegian Women's Public Health Association. The Anders Jahre's Fund for Promotion of Science, The Isberg's Legacy, The Grethe Harbitz Legacy and The Eckbo's Legacy for financial support. We are also indebted to Ingrid Holm for excellent technical assistance.

1 Ebringer A, Ptaszynska T, Corbett M, et al. Antibodies to Proteus in rheumatoid arthritis. Lancet 1985; ii: 305-7.

Rogers P, Hassan J, Bresnihan B, Feighery C, Whelan A Antibodies to Proteus in rheumatoid arthritis. $\mathrm{Br} f$ Rheumatol 1988; 27 (suppl 2): 90-4.

3 Deighton C M, Gray J W, Bint A J, Walker D J. Anti-Proteus antibodies in rheumatoid arthritis same-sexed sibships. $B$ f Rheumatol 1992; 31: 241-5.

4 McDonagh J, Gray J, Sykes $\mathrm{H}$, Walker D J, Bint A J, Deighton C M. Anti-Proteus antibodies and Proteus organisms in rheumatoid arthritis: a clinical study. $B r \mathcal{F}$ Rheumatol 1994; 33: 32-5.

5 Kjeldsen-Kragh J, Haugen M, Borchgrevink C F, et al. Controlled trial of fasting and one-year vegetarian diet in heumatoid arthritis. Lancet 1991;338: 899-902.

6 Kjeldsen-Kragh J, Haugen M, Førre $\emptyset$, Laache H, Malt UF Vegetarian diet for patients with rheumatoid arthritis: can the clinical effects be explained by the psychological characteristics of the patients? Br $\mathcal{F}$ Rheumatol 1994; 33 . 569-75.

7 Davis M J, Dawes P T, Fowler P D, et al. Comparison and 
8 Midtvedt T, Johansson G, Carlstedt-Duke B, Midtvedt A-C, Norin K E, Gustafsson J- $\AA$. The effect of a shift from a mixed to a lacto-vegetarian diet on some intestinal microflora associated characteristics. Microb Ecol Health Dis 1990; 3: 33-8.

9 Peltonen R, Ling W-H, Hänninen O, Eerola E. An uncooked vegan diet shifts the profile of human fecal microflora: computerized analysis of direct stool sample microflora: computerized analysis of direct stool sample gas-liquid chromatography profiles of bacterial cell
fatty acids. Appl Environ Microbiol 1992; 58: 3660-6.

10 Peltonen R, Kjeldsen-Kragh J, Haugen M, et al. Changes of faecal flora in rheumatoid arthritis during fasting and one-year vegetarian diet. $B r f$ Rheumatol 1994; 33: 638-43.

11 Wilson C, Corbett M, Ebringer A. Increased isolation of Proteus mirabilis species from rheumatoid arthritis patients compared to osteoarthritis patients and healthy controls. Br f Rheumatol 1990; 29 (suppl 2): 99.
12 Ebringer A, Wilson C, Ahmadi K, Corbett M, Rashid T, Shipley $M$. Rheumatoid arthritis as a reactive arthritis to proteus infection: prospects for therapy. In: Machtey I ed. Progress in Rheumatology, vol 5. Petach Tiqva, Israel: Rheumatolgy Service, Hasharon Hospital, Golda Medical Centre, 1993; 77-83.

13 Adlercreutz H, Fotsis T, Bannwart C, et al. Determination of urinary lignans and phytoestrogen metabolites, potential antiestrogens and anticarcinogens, in urine of potential antiestrogens and anticarcinogens, in urine of 25: 791-7.

14 Ito $K$, Iida $T$, Ichino $K$, Tsunezuka $M$, Hattori $M$, Namba T. Obovatol and obovatal, novel biphenyl ether lignans from the leaves of Magnolia obovata Thunb. Chem Pharm Bull 1982; 30: 3347-53.

5 Deighton C M, Gray J, Bint A J, Walker D J. Specificity of the proteus antibody response in rheumatoid arthritis. Ann Rheum Dis 1992; 51: 1206-7. 